\title{
Antagonistic potential and histopathology of Meloidogyne javanica on Macrotyloma axillare cv. Java
}

\section{Angélica Miamoto* ${ }^{1}$, Andressa Cristina Zamboni Machado ${ }^{2}$, Orazília França Dorigo ${ }^{2}$, Thaísa Muriel Mioranza ${ }^{1}$, Heriksen Higashi Puerari ${ }^{1}$, Beatriz Almeida e Silva ${ }^{3}$, Vítor Vargas Schwan ${ }^{1}$, Cláudia Regina Dias Arieira ${ }^{3}$}

\author{
${ }^{1}$ State University of Maringá, Post Graduate in Agronomy, Maringá, PR, Brazil \\ ${ }^{2}$ Agronomic Institute of Paraná, Londrina, PR, Brazil \\ ${ }^{3}$ State University of Maringá, Department of Agronomic Science, Umuarama, PR, Brazil
}

*Corresponding author: angelicamiamoto@gmail.com

\section{Abstract}

\begin{abstract}
Root-knot nematodes are obligate parasites, so changes at their feeding sites can limit their development. Alterations to feeding sites is one of the main actions taken by antagonistic plants. The aim of this study was to assess the response and histopathology of interactions between Meloidogyne javanica and the roots of Macrotyloma axillare cv. Java. The penetration and development of the nematode was assessed from 8 to 30 days after inoculation (DAI) with 3000 eggs + second-stage juveniles (J2) of M. javanica. The reproduction factor (RF) was assessed at $60 \mathrm{DAl}$, with two inoculation levels, 700 and 1000 eggs $+\mathrm{J} 2$, and the changes in the development and histopathology of $M$. javanica was assessed at 10, 15 and 30 DAl. Suscetible soybean was used as a control. The development of nematodes at the third (J3) and fourth juvenile (J4) stages was delay, despite the presence of J2 inside the roots, and no adult females were found in the $M$. axillare cv. Java roots. RF was 0.31 and 0.39 for $M$. axillare cv. Java and 3.40 and 4.52 for soybean at inoculation levels of 700 and 1000 eggs $+\mathrm{J} 2$, respectively. The feed cells in M. axillare cv. Java could not effectively nourish the nematode, which led to deformed females 30 DAl. The feed cells and nematode development, however, were normal in soybean. $M$. axillare $\mathrm{cv}$. Java was resistant to $M$. javanica and had an antagonistic potential, because it did not prevent the nematode from penetrating the roots but had a negative effect on $M$. javanica due to the inefficiency of the feeding site.
\end{abstract}

Keywords: Antagonistic; Crop Rotation; Leguminous; Resistance; Root-knot nematode.

\section{Introduction}

The genus Meloidogyne, often known as root-knot nematodes, contains the main species of plant parasitic nematodes due to its wide geographical distribution and broad range of hosts (Jones et al., 2013). More than 100 Meloidogyne species parasitize various plants worldwide. Economic losses are estimated at US\$ 157 billion globally (Abad et al., 2008), with crop losses of about $30-50 \%$ in banana, tobacco, cassava, soybean and other crops (Fourie et al., 2001; Coyne et al., 2006). Meloidogyne javanica (Treub) Chitwood and $M$. incognita (Kofoid and White) Chitwood are among the main species that affect the soybean (Castro et al., 2003).

Parasitism by root-knot nematodesis complex and involves the formation of feeding sites characterized by hypertrophic and multinucleated cells (Williamson; Gleason, 2003; Abad et al., 2009). The nematodes absorb the nutrients they need for their development from these cells. Any interference at the feeding site can impair the development of the nematode and lead to its death (Williamson; Hussey, 1996; Faria et al., 2003).

Plants resistant to the nematode do not necessarily inhibit it, but the nematode can disrupt the formation of nourishing cells that become less nourishing (Moritz et al., 2008a). In addition to the formation of ineffective feeding sites, these plants may have other natural defensive responses to pathogenic attacks, such as hypersensitive reactions (HRs) and the sudden and programmed death of infected tissues and tissues surrounding the feeding site (Watanabe; Lam, 2004).

The genetic improvement of plants has focused on nematode resistance. Some antagonistic plants, such as Crotalaria species, are examples of the formation and maintenance of the feeding sites. The efficiency of such species in controlling these nematodes has been broadly demonstrated (Inomoto et al., 2006; Ohara et al., 2012; Danahap; Wangang, 2015). Histopathological analyses applied to Crotalaria spectabilis Roth and $C$. juncea L. parasitized by $M$. javanica indicated the formation of fewer hypertrophic giant cells, which have few nuclei and lack vacuoles. These effects lowered the efficiency of nematode feeding, and HRs were induced around the nourishing cells in both Crotalaria species (Silva et al., 1990). Antagonistic activity is known for some species, but other species have been rarely studied. Macrotyloma axillare (E. 
Mey.) Verdc. cv. Java, which belongs to the Family Fabaceae, is a cross between two other cultivars: Archer and Guata. This cultivar has been used in recovery programs focused on degraded soils and revegetation due to its ability to protect soil as a cover crop (Silva et al., 2007). Previous studies have found that this plant has the potential to control $M$. javanica because of its possible antagonistic effect; the nematode can penetrate the roots but has limited reproduction (Miamoto et al., 2016).

Macrotyloma axillare $\mathrm{cv}$. Java has received little attention but may be an option for crop rotation tocontrol nematodes. The aim of this study was to assess the penetration, development and reproduction of $M$. javanica inthe roots of $M$. axillare $\mathrm{cv}$. Java and to conduct a histopathological study of the infection caused by the nematode.

Results

\section{Penetration of $M$. javanica in roots of M. axillare cv. Java and soybean}

The interaction between the factors 'time' and 'plant' was significant based on the number of $\mathrm{J} 2$ in the roots. Fewer $\mathrm{J} 2$ were found in the $M$. axillare $\mathrm{cv}$. Java roots than the soybean roots 10,12 and $14 \mathrm{DAl}$, but soybean and $M$. axillare cv. Java had similar numbers of $\mathrm{J} 2$ at the other times (Table 1 ). The factor 'time', however, was not significant for either plant. 'Plant' and 'time' did not interact significantly for the number of third-stage juveniles (J3), but both factors was individually significant. Fewer J3 were in the $M$. axillare $\mathrm{cv}$. Java roots (average 1.31) than the soybean roots (7.39), whereas the means were lower for the evaluation of the factor 'time' $8 \mathrm{DAl}$, followed by the values recorded 10, 12, 14 and 16 DAI, when they were compared to the other evaluations (data not shown).

The interaction between the factors was significant for the number of fourth-stage juveniles (J4), except for 8 and 16 DAI when the numbers of juveniles in $M$. axillare cv. Java and soybean were similar. The number of J4 was higher in soybean roots at all times (Table 1). The evaluation time applied to each plant indicated that soybean had the lowest value $8 \mathrm{DAl}$, followed by the values assessed 10 and $16 \mathrm{DAl}$, when they were compared to the other times. The number of J4 in $M$. axillare cv. Java, however, did not differ significantly at the different DAI; the mean number of J4 varied from 0.0 to 0.6 (Table 1).

The first evaluation, conducted $8 \mathrm{DAI}$, identified J3 and J4in the soybean roots, whereas $\mathrm{J} 3$ and $\mathrm{J} 4$ in $M$. axillare $\mathrm{cv}$. Java were identified 10 and 14 DAl, respectively (Table 1 ).

Females in the soybean roots were first observed 14 DAl, but no adult females were observed in $M$. axillare $\mathrm{cv}$. Java until the end of the evaluations (Table 1 ). The interactions were significant, with differences between the plants from 20 to 30 DAl, and the number of females was always higher in the soybean roots. The evaluation time applied to soybean therefore indicated higher mean female numbers during this evaluation period, and the mean number of females in $M$. axillare cv. Java did not differ significantly during the entire evaluation period.

Finally, the total number of nematodes indicated that the means were higher in soybean at all times evaluated, except for 8 and 16 DAl when the means in different plants did not differ significantly from each other (Table 1). The mean factor 'time'was lowest 8 and 16 DAl in soybean and at the first four evaluations, 8, 10, 12 and 14 DAl, in M. axillare cv. Java.

The number of $\mathrm{J} 2$ per gram of root was higher in $M$. axillare $\mathrm{cv}$. Java roots at all times evaluated, except for 12 and 14 DAI (Table 2). 'Time' was a significant factor for M. axillare cv. Java, which had the highest means at $8 \mathrm{DAl}$, followed by 16 and 18 DAI. The number of J3 per gram ofroot was higher in soybean 10,12 and $14 \mathrm{DAl}$, the same as $28 \mathrm{DAl}$ in M. axillare cv. Java, but did not differ significantly at the other times. The factor 'time' did not differ significantly in soybean, and the means were highest in M. axillare cv. Java at 28 DAl (Table 2).

Only the factor 'plant' significantly affected the number of $\mathrm{J} 4$ per gram of root, and the soybean mean (1.38) was higher than for M. axillare cv. Java (0.43) (data not shown). The number of females per gram of root was highest in soybean roots after 20 DAl. 'Time' was only significant for soybean, which had highest means at the same evaluation time (Table 2).

The total number of nematodes per gram of root was highest in M. axillare cv. Java $8 \mathrm{DAl}$, followed by 16,18 and 28 DAl but did not differ significantly for soybean (Table 2).

\section{Reproduction factor of $M$. javanica in roots of $M$. axillare $c v$. Java and soybean}

'Time' and 'plant' did not significantly interact for the total number of nematodes, nematodes per gram of root (NG) or the reproduction factor (RF), but each factor individually differed significantly (Table 3 ). The factors 'inoculum level' and 'plant' significantly affected the total number of nematodes (TN), and TN was higher for the inoculation with 1000 nematodes than the inoculation with 700 nematodes; TN was lower for M. axillare cv. Java than soybean (Table 3).

RF and NG differed significantly between the between plants and inoculum levels, and were lower in $M$. axillare cv. Java than soybean (Table 3). RF was 0.31 and 0.39 in M. axillare cv. Java and 3.40 and 5.52 in soybean inoculated with 700 and 1000 nematodes, respectively (Table 3 ).

\section{Histopathology of the interaction between M. javanica and M. axillare cv. Java}

The histopathological study conducted at 10 DAl assessed the formation of feeding sitesin both plants. Granulating nourishing cells with up to five nuclei formed in soybean (Figure 1A). The cells were unorganized and hypertrophic in the $M$. axillare $\mathrm{cv}$. Java roots (Figure $1 \mathrm{~B}$ ).

The soybean samples at 15 DAl indicated the presence of nematodes and the normal formation of feeding sites and multinucleated giant cells (Figure $1 \mathrm{C}$ ). The Java samples also indicated the presence of nematodes but no feeding sites, only a slight cellular disorganization (Figure 1D). Adult females and feeding sites had fully developed by $30 \mathrm{DAl}$, with characteristic cellular modifications at the feeding sites, including multinucleated giant cells, thick walls, dense cytoplasm and small vacuoles (Figure 1E), indicating normal nematode development. Some females in $M$. axillare cv. Java were deformed (Figure 1F), probably due to the incomplete 


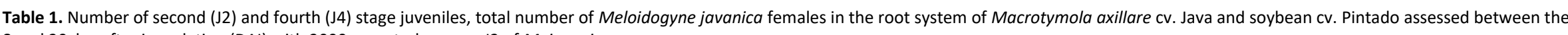
8 and 30 day after inoculation (DAI) with 3000 nematode eggs $+\mathrm{J} 2$ of $M$. javanica.

\begin{tabular}{|c|c|c|c|c|c|c|c|c|c|c|c|c|c|c|c|c|c|c|c|c|c|c|c|c|}
\hline \multirow{3}{*}{ Trat. } & \multicolumn{24}{|c|}{ Evaluation Time } \\
\hline & 8 & & 10 & 1 & 2 & & 4 & 1 & & & 18 & 2 & 0 & 2 & 22 & 2 & & 2 & 26 & & 28 & 3 & 30 & \\
\hline & \multicolumn{24}{|l|}{ J2 } \\
\hline Soybean & 6.7 & $\mathrm{aA}$ & 10.2 & $a A$ & 12.0 & $\mathrm{aA}$ & 10.5 & $\mathrm{aA}$ & 6.2 & $\mathrm{aA}$ & 5.2 & $\mathrm{aA}$ & 11.5 & $\mathrm{aA}$ & 5.5 & $a A$ & 5.5 & $\mathrm{aA}$ & 10.2 & $a A$ & 9.2 & $\mathrm{aA}$ & 6.7 & $\mathrm{aA}$ \\
\hline \multirow[t]{2}{*}{ Java } & 5.7 & $\mathrm{aA}$ & 5.0 & bA & 3.7 & $\mathrm{bA}$ & 2.2 & bA & 9.2 & $\mathrm{aA}$ & 11.0 & $\mathrm{aA}$ & 6.0 & $\mathrm{aA}$ & 5.7 & $\mathrm{aA}$ & 8.2 & $\mathrm{aA}$ & 6.7 & $\mathrm{aA}$ & 6.0 & $\mathrm{aA}$ & 7.5 & $\mathrm{aA}$ \\
\hline & \multicolumn{24}{|c|}{ CV (\%) 27.34} \\
\hline \multirow{4}{*}{$\begin{array}{l}\text { Trat. } \\
\text { Soybean } \\
\text { Java }\end{array}$} & \multicolumn{24}{|c|}{$J 4$} \\
\hline & 0.5 & $\mathrm{aC}$ & 7.5 & $a A$ & 14.7 & $a B$ & 6.7 & $\mathrm{aA}$ & 5.7 & $\mathrm{aB}$ & 14.2 & $\mathrm{aA}$ & 17.7 & $a A$ & 7.0 & $a A$ & 9.7 & $a A$ & 8.5 & $a A$ & 11.5 & $\mathrm{aA}$ & 10.0 & $\mathrm{aA}$ \\
\hline & 0.0 & $\mathrm{aA}$ & 0.0 & bA & 0.0 & $\mathrm{bA}$ & 0.2 & bA & 0.7 & $\mathrm{aA}$ & 0.2 & bA & 0.0 & bA & 0.2 & $\mathrm{bA}$ & 0.5 & $\mathrm{bA}$ & 0.2 & bA & 0.7 & bA & 0.7 & $\mathrm{bA}$ \\
\hline & \multicolumn{24}{|c|}{ CV (\%) 46.01} \\
\hline Trat. & \multicolumn{24}{|c|}{ Females } \\
\hline Soybean & 0.0 & $\mathrm{aB}$ & 0.0 & $\mathrm{aB}$ & 0.0 & $\mathrm{aB}$ & 0.5 & $\mathrm{aB}$ & 0.0 & $\mathrm{aB}$ & 1.5 & $\mathrm{aB}$ & 5.5 & $\mathrm{aA}$ & 3.0 & $\mathrm{aA}$ & 3.7 & $\mathrm{aA}$ & 3.0 & $\mathrm{aA}$ & 7.2 & $\mathrm{aA}$ & 4.2 & $\mathrm{aA}$ \\
\hline \multirow[t]{2}{*}{ Java } & 0.0 & aA & 0.0 & aA & 0.0 & aA & 0.0 & aA & 0.0 & aA & 0.0 & $\mathrm{aA}$ & 0.0 & bA & 0.0 & bA & 0.0 & bA & 0.0 & bA & 0.0 & bA & 0.0 & bA \\
\hline & \multicolumn{24}{|c|}{ CV (\%) 61.31} \\
\hline Trat. & \multicolumn{24}{|c|}{ Total Number } \\
\hline Soybean & 8.7 & $\mathrm{aB}$ & 26.2 & $\mathrm{aA}$ & 34.7 & $\mathrm{aA}$ & 24.0 & $\mathrm{aA}$ & 15.5 & $\mathrm{aB}$ & 28.7 & $\mathrm{aA}$ & 42.2 & $\mathrm{aA}$ & 25.5 & $\mathrm{aA}$ & 26.7 & $\mathrm{aA}$ & 28.7 & $\mathrm{aA}$ & 36.7 & $\mathrm{aA}$ & 33.2 & $\mathrm{aA}$ \\
\hline \multirow[t]{2}{*}{ Java } & 5.7 & $a B$ & 5.2 & bB & 4.0 & bB & 2.5 & $b B$ & 10.7 & $a A$ & 12.7 & bA & 8.5 & bA & 7.5 & bA & 10.5 & bA & 9.0 & bA & 10.2 & bA & 10.0 & bA \\
\hline & \multicolumn{24}{|c|}{ CV (\%) 19.13} \\
\hline
\end{tabular}

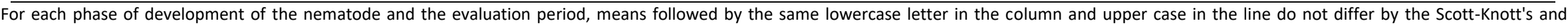
Bonferroni $\mathrm{T}$ test at $5 \%$ probability. Trat. = treatment. $\mathrm{CV}=$ coefficient of variation.

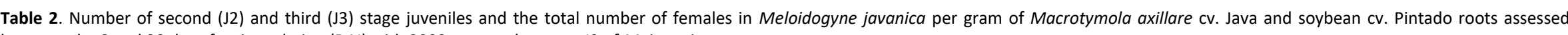
between the 8 and 30 day after inoculation (DAl) with 3000 nematode eggs $+\mathrm{J} 2$ of $M$. javanica.

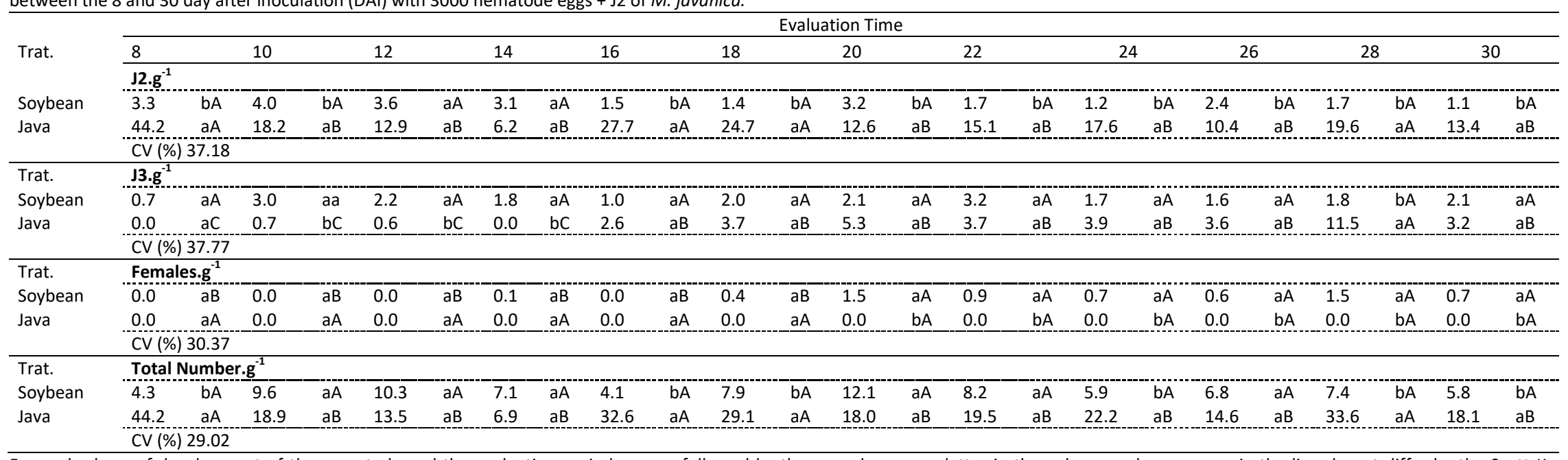

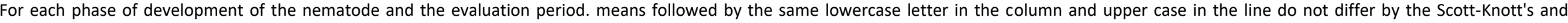
Bonferroni $\mathrm{T}$ test at $5 \%$ probability. Trat. = treatment. $\mathrm{CV}=$ coefficient of variation. 


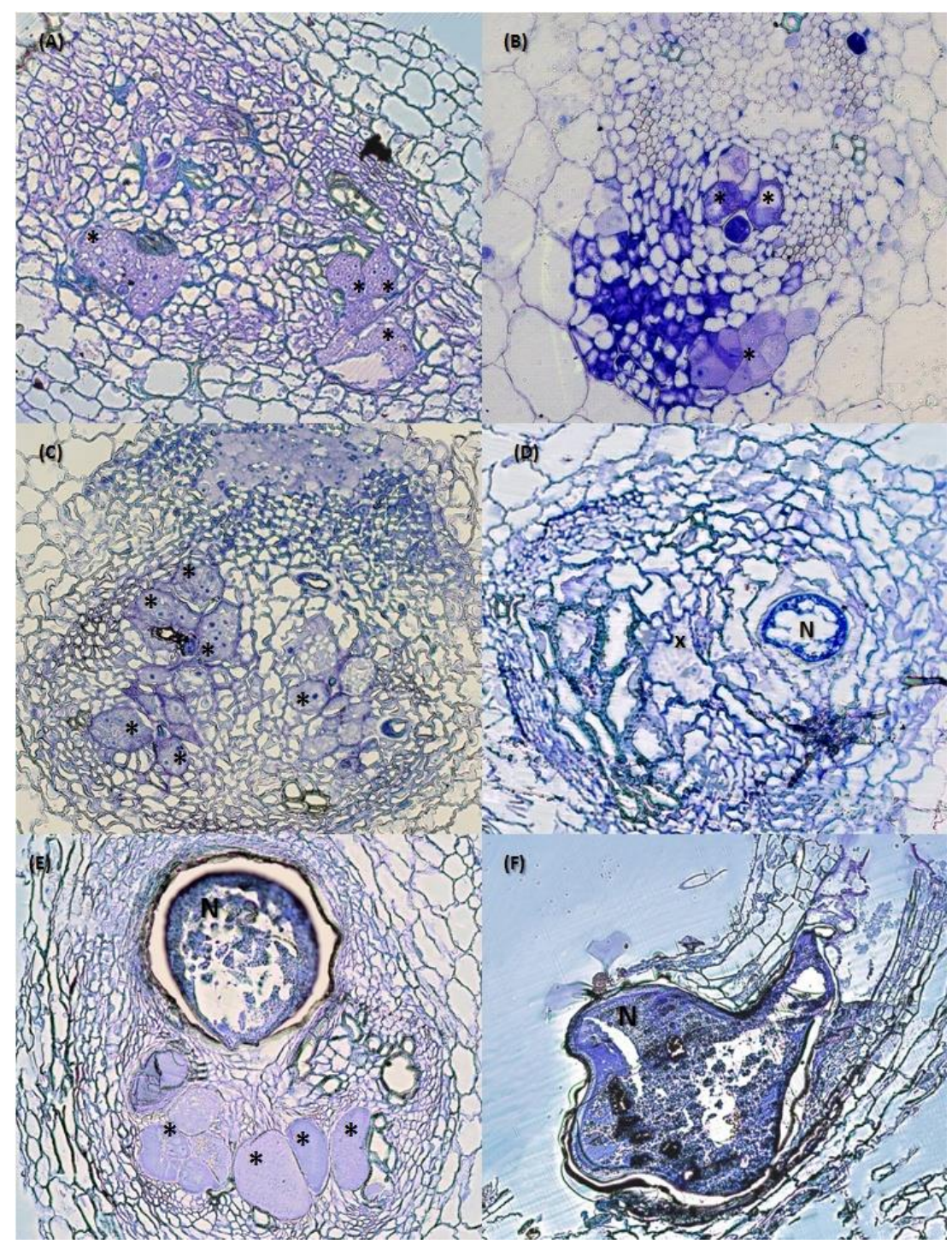

Fig 1. Effect of nematodes on roots of Macrotyloma axillare. A: Feeding sites (multinucleated giant cells) formed through the parasitism of Meloidogyne javanica in soybean at 10 DAl. B: Feeding site (giant cells without apparent nuclei) formed by the parasitism of $M$. javanica in Macrotymola axillare cv. Java at 10 DAl. C: Feeding site (multinucleated giant cells) formed by the parasitism of $M$. javanica in soybean at 15 DAI. D: M. javanica parasitizing M. axillare cv. Java roots at $15 \mathrm{DAl}$, cell disorganization and malformed feeding site. E: $M$. javanica female parasitizing soybean roots at $30 \mathrm{DAl}$, six granulating and multinucleated cells. F: Deformed $M$. javanica female in $M$. axillare $\mathrm{cv}$. Java root at $30 \mathrm{DAl} .{ }^{*}=$ giant cells, $\mathrm{N}=$ nematode, $\mathrm{x}=$ cell disorganization.

Table 3. Total number of nematodes (NT), number of nematodes per gram of root (NG) and reproduction factor (FR) of Meloidogyne javanica in Macrotyloma axillare cV. Java and soybean roots, inoculated with initial population (IP) of 700 and 1000 eggs $+\mathrm{J} 2$ of $M$. javanica.

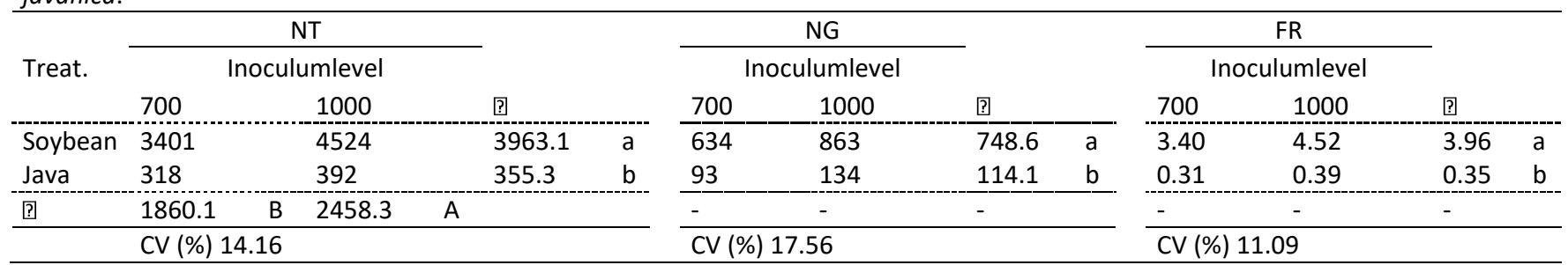

For each inoculum level means followed by the same letter in the column do not differ by the Bonferroni $\mathrm{T}$ test at $5 \%$ probability. Trat. $=$ treatment. $\mathrm{CV}=$ coefficient of variation. 
formation of the feeding sites or to reduced hypersensitivity, although we found no evidence of this mechanism in any of the slide fragments.

\section{Discussion}

M. javanica efficiently penetrated the $M$. axillare cv. Java roots; the number of $\mathrm{J} 2$ penetrating this plant was similar to the number of $\mathrm{J} 2$ in the soybean roots. The number of nematodes per gram of root was higher in $M$. axillare cv. Java than soybean. J3 and J4, however, appeared later; no females were found in $M$. axillare cv. Java. We thus hypothesized that $M$. axillare $\mathrm{cv}$. Java was antagonistic to $M$. javanica. Antagonist plants are characterized by their mode of action, because they have a negative effect on nematode development in the root system (Chitwood, 2002). Their mode of action can change depending on the species; these changes can be characterized by repelling the nematode due to the production of allelopathic compounds or by allowing penetration, but they inhibit the life cycle of the nematode because of the resistance mechanisms (Chitwood, 2002; Nyczepir; Thomas, 2009).

The antagonistic potential of this culture to control $M$. javanica was recently reported. Nematode penetration in the root system was higher in $M$. axillare $\mathrm{cv}$. Java than soybean, but RF was lower and similar to that for the Crotalaria species. This result indicated that the nematode life cycle was negatively affected by the culture (Miamoto et al., 2016). Miamoto et al. (2018) also reported that the plants had an antagonistic potential against $M$. incognita.

The response of $M$. axillare $\mathrm{cv}$. Java to $M$. javanica was similar to the responses reported for other pathosystems involving antagonistic plants, such as Cajanus cajan L. (Mill) cv. Fava Larga $\times$ Heterodera glycines Ichinohe (Valle et al., 1997) and C. cajancv. IAPAR $43 \times$ M. javanica (Miamoto et al., 2016). Nematodes penetrated the roots of these plants but did not complete their life cycle. The result was similar for $C$. spectabilis and Meloidogyne spp.; the plants attracted the nematodes to the root system but did not allow the nematodes to efficiently reproduce and developto the next stage (Curto et al., 2015; Miamoto et al., 2016).

Plant antagonism against nematodes can also occur due to the production of toxic substances, as in Tagetes spp., whose antagonistic effect has been attributed to the production of $\alpha$ terthienyl. In addition to inhibiting nematode development after root penetration, $\alpha$-terthienyl directly affects egg hatching and the juveniles in the soil; it thus impairs infectionby the pathogen (Debprasad et al., 2000; Hussain et al., 2011; Ferreira et al., 2013). Similarly, the production of substances by $C$. cajan toxic to the nematode can inactivate and kill M. exigua Goeldi juveniles (Amaral et al., 2002). The chemical composition ofextracts of $M$. axillare cv. Java should thus be studied in the future.

The reaction of a resistant plant can be similar to an antagonist, as observed in studies about the genotype of cotton species resistant to $M$. incognita, in which most of the nematodes penetrating the roots did not pass the J2 stage, because they did not establish efficient feeding sites (Carneiro et al., 2005). A study of the resistance of soybean cultivars CD 214 RR and CD 203 susceptible and resistant, respectively, to $M$. paranaensis was due to nematode penetration and initial development, with J3 formation unaffected but with the number of females affected (Moritz et al., 2008b). This result was similar to that for M. axillare cv. Java in our study, in which no adult females developed, despite the initial penetration and development.

The histopathological examination found that the feeding site was inefficient for nourishing the nematodes in the interaction between $M$. Javanica and $M$. axillare cv. Java, because the females were atrophic. These results were similar to those for white Avena sativa L. cv. IPR Afrodite infected with $M$. incognita, which had underdeveloped parasites at 18 DAl (Marini et al., 2016). Marini et al. (2016) also reported the formation of small and malformed giant cells, indicating that the nematode could induce the formation of the feeding sites but could not establish complete differentiation, thereby influencing its own development.

Dysfunctional feeding sitesmay be associated with HRs, which kill cells adjacent to the infection site (Moffett et al., 2002). This reaction has been observed in the pathosystems of $M$. exiguaand coffee trees (Anthony et al., 2005) and of $M$. incognita and cotton (Motta et al., 2012), demonstrating that incompatible interactions between nematodes and plants can cause localized death in tissues adjacent to the nematode feeding site. Such plant defensive reactions may not limit parasite invasion or the induction of feeding sites but may limit nematode growth and development (Williamson; Gleason, 2003).

Our results indicated a lack of necrosis, suggesting HRs, but the stimulus for the formation and maintenance of giant cells differed between $M$. axillare cv. Java and soybean. This result corroborates other studies, including the interaction between the cotton genotypes resistant to $M$. incognita, which developed HRs but formed small feeding sites with small cells, apparent extensive cell disorganization and no thickening of the secondary membrane wall (Carneiro et al., 2005). Similarly, the pathosystem for the coffee cV. Apoatã IAC 2258 and M. exigua demonstrated that the lack of resistance was not only due to HR but also to a set of defensive responses constituted, or induced, after the infection by the nematode. These responses led to the malformation of the feeding site, J2 emigration and the inhibition of nematode development and reproduction. Thus, resistant plants have mechanisms that prevent the establishment of feeding sites, because fewer nourishing cells form. These cells are smaller and consequently can less efficiently feed the nematode, impairing its development (Moritz et al., 2008b). The resistant plants and some antagonistic species therefore did not prevent nematode penetration but compromised its development. The nematodes could die before completing their life cycle.

\section{Materials and Methods}

\section{Experimental area and design}

The experiments were conducted in a greenhouse and laboratory at the State University of Maringá $\left(23^{\circ} 47^{\prime} 28.4^{\prime \prime} \mathrm{S}\right.$, $53^{\circ} 15^{\prime} 24.0^{\prime \prime} \mathrm{W} ; 379 \mathrm{~m}$ a.s.I.). The study had a completely randomized design for each of two experiments, based on a $2 \times 12$ factorial arrangement ( 2 plants and 12 evaluation times) for the penetration test and a $2 \times 2$ arrangement ( 2 plants and 2 inoculation levels) for the reproduction test. 
Seedlings of $M$. axillare cv. Java and the soybean cv. Pintado (control) were obtained by germination in polyethylene trays containing a commercial substrate for evaluating penetration. These seedlings were transplanted to $700-\mathrm{mL}$ pots containing a 1:1 mixture of soil and sand15 $\mathrm{d}$ after germination. The mixture was autoclaved at $120^{\circ} \mathrm{C}$ for $2 \mathrm{~h}$.

\section{Penetration of $M$. javanicainto the roots of $M$. axillare $c v$. Java and soybean}

The seedlings were inoculated with an initial populationof 3000 eggs + second-stage juveniles (J2) of $M$. javanica per plant two days after transplantation. The nematode suspension was deposited in four equidistant holes (approximately $2 \mathrm{~cm}$ deep) in the soil around each plant. The nematodes used as inoculum were obtained from a pure population raised in tomato plants (cv. Santa Clara) under greenhouse conditions. They were extracted from the root system based on the methodology by Hussey and Barker (1973) and adapted by Boneti and Ferraz (1981).

Four plants of each treatment were harvested every two days from 8 to 30 days after inoculation (DAI) to assess nematode penetration and development. The root systems of these plants were carefully separated from the shoots, washed and deposited on paper towels to remove excess water. The roots were then weighed and stained with acid fuchsin (Byrd Junior et al., 1983). Temporary slides with root fragments from each plant were prepared and analyzed using a light microscope at a magnification of $100 \times$. The number of nematodes penetrating the root systems was assessed, and the developmental stage was classified as juveniles in the second, third and fourth stages (J2, J3 and J4, respectively) or females.

\section{Reproduction factor (RF) for $M$. javanicain theroots of $M$. axillare cv. Java and soybean}

Nematode reproduction was also assessed when the plants were inoculated two days after transplantation with two initial inoculations (II) of 700 and 1000 eggs $+J 2$ of M. javanica. Plants were maintained in the greenhouse for 60 days, and the root systems were then collected, washed and weighed. The nematodes were extracted as described above and quantified using Peters slides under a light microscope to evaluatethe final population (FP). RF for the nematodes was then calculated following the method by Oostenbrink (1966), in which $\mathrm{RF}=\mathrm{PF} / \mathrm{PI}$. Seven replicates were assessed in each treatment.

\section{Statistical analysis}

The recorded data were subjected to analyses of variance and transformed as $\sqrt{(x+0,5)}$. The Shapiro Wilk test was used to evaluate normal distributions. The means of the factor 'plant' were compared using the Bonferroni $\mathrm{T}$ test, whereas 'time' was compared using the Scott-Knott test, both at $5 \%$ probability level. The tests were conducted using Sisvar software.

\section{Histological analysis}

M. axillare cv. Java and soybean seeds were sowed in 200-mL pots and inoculated with 1000 eggs $+\mathrm{J} 2$ of M. javanica $15 \mathrm{~d}$ after germination for evaluating the histopathology.

Four roots were carefully removed and washed for the evaluations conducted 10, 15 and 30 DAl. The roots were prepared for further fragments based on Pergard et al. (2005). Twenty root fragments (approximately $0.5 \mathrm{~cm}$ ) were sectioned, and root areas with visible galls were selected and immersed in a fixer ( $2 \%$ paraformaldehyde and $1 \%$ glutaraldehyde in $0.1 \mathrm{M}$ phosphate buffer at $\mathrm{pH} 7.00$ ) under continuous shaking. The root samples were then dehydrated in $10,30,50,70,80$, 90 and $100 \%$ ethanol, and the fragments were deposited in microtubes and impregnated with resin (Technovit 7100), based on the manufacturer's protocol. Fragments $(1-2 \mu \mathrm{m})$ were sectioned with a Luptec MRP 2015 ultramicrotome and deposited in drops of distilled water on microscope slides over a heating plate to dry and fix the fragments. The samples were then stained with $0.5 \%$ toluidine blue and observed in a light microscope to visualize nematode development and the formation of feeding sites. The selected histopathological fragments were photographed for analyzingand comparing $M$. axillare $\mathrm{cv}$. Java and soybean.

\section{Conclusions}

Macrotyloma axillare cv. Java was resistant to $M$. javanica and was potentially antagonistic. It did not prevent nematodes from penetrating the roots but had a negative effect on the life cycleby the formation of inefficient feeding sites for nourishing the nematode.

\section{Acknowledgments}

Thanks to CAPES for the master's degree scholarship for the first author and to CPNq for the research productivity scholarship for the last author.

\section{References}

Abad P, Castagnone-Sereno P, Rosso MN, Almeida EJ, Favery B (2009) Invasion, feeding and development. In: Perry, R. N., Moens, M., Starr, J. L. (Eds). Root-knot Nematodes. Wallingford, CABI Publishing (pp.162-181).

Abad P, Gouzy J, Aury MJ (2008) Genome sequence of the metazoan plant-parasitic nematode Meloidogyne incognita. Nat. Biotechnol. 26(1), 909-915.

Anthony F, Topart P, Martinez A, Silva M, Nicole M (2005) Hypersensitive-like reaction conferred by de Mex-1 resistance gene against Meloidogyne exigua in coffee. Plant Pathol. 54(1), 476-482.

Amaral DR, Oliveira DF, Campos VP, Carvalho DA (2002) Efeito de alguns extratos vegetais na eclosão, mobilidade, mortalidade e patogenicidade de Meloidogyne exigua do cafeeiro. Nematol Bras. 26(1), 43-46.

Boneti JIS, Ferraz S (1981) Modificação do método de Hussey e Barker para extração de ovos de Meloidogyne exigua de raízes de cafeeiro. Fitopatol Bras. 6(3), 553.

Byrd Junior DW, Kirpatrick J, Barker KR (1983) An improved technique for clearing and staining plant tissues for detection of nematodes. J Nematol. 15(1), 141-143. 
Carneiro RMDG, Neves DI, Falcão R, Paes NS, Cia E, Sá MFG (2005) Resistência de genótipos de algodoeiro a Meloidogyne incognita raça 3: Reprodução e Histopatologia. Nematol Bras. 29(1), 1-10.

Castro JMC, Lima RD, Carneiro RMDG (2003) Variabilidade isoenzimática de populações de Meloidogyne spp. provenientes de regiões brasileiras produtoras de soja. Nematol Bras. 27(1), 1-2.

Chitwood DJ (2002) Phytochemical based strategies for nematode control. Annu Rev Phytopathol. 40, 221-249.

Coyne DL, Toko M, Andrade M (2006) Meloidogyne spp. and associated galling and damage on cassava in Kenya and Mozambique. Afr Plant Protect. 12(1), 25-26.

Curto G, Dallavalle E, Santi R, Casadei N, D'Avino L, Lazzeri L (2015) The potential of Crotalaria juncea L. as a summer green manure crop in comparison to Brassicaceae catch crops for management of Meloidogyne incognita in the Mediterranean area. Eur J Plant Pathol. 142(4), 829-841.

Danahap LS, Wonang DL (2016) Antinematicidal efficacy of root exudates of some Crotalaria species on Meloidogyne incognita root-knot nematode Kofoid and White Chitwood isolated from infected Lycopersicum esculentum L. tomato plant. IJEST. 5(3), 76-84.

Debprasad R, Prasad D, Singh RP, Ray D (2000) Chemical examination a dantinemic activity of marigold (Tagetes erecta L.) flower. Plant Protect Sci. 8(2): 212-217.

Faria CMDR, Salgado SML, Campos HD, Resende MLV, Campos VP, Coimbra JL (2003) Mecanismos de ataque e defesa na interação nematóide-planta. Rev Ann Patol Plantas. 11(1), 373-410.

Ferreira ICM, Silva GS, Nascimento FS (2013) Efeito de extratos aquosos de espécies de Asteraceae sobre Meloidogyne incognita. Sum Phytopathol. 39(1), 40-44.

Fourie H, Mcdonald AH, Loots GC (2001) Plant-parasitic nematodes in field crops in South Africa. 6. Soybean. Nematol. 3(1), 447-454.

Hussain MA, Mukhtar T, Kayani MZ (2011) Efficacy evaluation of Azadirachta indica, Calotropis procera, Datura stramonium and Tagetes erecta against Root-knot nematodes Meloidogyne incognita. Pak J Botany. 43(1), 197204.

Hussey RS, Barker KR (1973) A comparison of methods colleting inocula of Meloidogyne spp. including a new technique. Plant Dis Rep. 57(1), 1025-1028.

Inomoto MM, Motta LCC, Beluti B, Machado ACZ (2006) Reação de seis adubos verdes a Meloidogyne javanica e Pratylenchu sbrachyurus. Nematol Bras. 30(1), 39-44.

Jones JT, Danchin EG J, Gaur HS, Heldes J, Jones MGK, Kikuchi T, Manzanilla-López R, Palomares-Rius JE, Wesemael WIMML, Perry R (2013) N.10 plant-parasitic nematodes in molecular plant pathology. Mol Plant Pathol. 14(1): 946-961.

Marini PM, Garbuglio DD, Dorigo OF, Machado ACZ (2016) Histological characterization of resistance to Meloidogyne incognita in Avena sativa. Trop Plant Pathol. 1(1), 1-7.

Miamoto A. Dias-Arieira CR, Cardoso MR, Puerari HH (2016) Penetration and reproduction of Meloidogyne javanica on leguminous crops. J Phytopatol. 164(11-12), 890-895.

Miamoto A, Dias-Arieira CR, Puerari HH, Mioranza TM, Pereira CB (2018) Antagonistic Effects of Java against Plant Parasitic Nematodes. J Agric Sci. 10(2), 289-300.
Moffett PG, Franham G, Peart J, Baucombe DC (2002) Interaction between domains of plant NBS-LRR protein in disease resistance-related cell death. EMBO J. 21(1), 45114519.

Moritz MP, Carneiro RG, Santiago DC, Medri ME, Correa A, Nakamura KC, Pingoni E, Gomes JC (2008a) Histopatologia Comparada das Raízes de Cultivares Suscetível e Resistente de Soja Inoculadas com Meloidogyne paranaensis. Nematol. Bras. 31(1), 41-49.

Moritz MP, Carneiro RG, Santiago DC, Nakamura KC, Pignoni E, Gomes JC (2008b) Estudo Comparativo da Penetração e Reprodução de Meloidogyne paranaensis em Raízes de Cultivares de Soja Resistente e Suscetível. Nematol Bras. 32(1):33-40.

Motta FC, Alves GCS, Giband M, Gomes ACMM, Souza FR, Mattos VS, Barbosa VHS, Barroso PAV, Nicole M, Peixoto JR, Rocha MR, Carneiro RMDG (2012) New sources of resistance to Meloidogyne incognita race 3 in wild cotton accessions and histological characterization of the defence mechanisms. Plant Pathol. 62(1), 1173-1183.

Nyczepir AP, Thomas SH (2009) Current and Future Management Strategies in Intensive Crop Production Systems. In: Perry, R. N., Moens, M., \& Starr, J. L Root-knot Nematodes. UK: CAB International, 2009. (pp. 412-435).

Ohara A, Daimon H, Momota Y, Chin DP, Mii M (1012) Plant regeneration from Crotalaria spectabilis hairy roots which showed inhibited growth of root-knot nematodes (Meloidogyne hapla and $M$. incognita) in vitro. Plant. Biotechnol. 29(5), 425-430.

Oostenbrink R (1966) Major characteristics of the relation between nematodes and plants. Meded. Landbouwhogeschool, 66(4), 46.

Pergard A, Brizzard G, Fazari A, Soucaze O, Abad P, Dijancaporalino C (2005) Histological species related to phenolics accumulation in Capsicumannum. Phytopatol. 95, 158-165.

Silva AH, Alves DS, Silveira HRO, Alvarenga ICA, Souza MF, Fernandes LF (2007) Aplicação de corretivos e fertilizantes para recuperação de áreas degradadas utilizando Macrotyloma axillare como cobertura vegetal no norte de Minas Gerais. Caminhos de Geografia. 8(22), 105-115.

Silva GS, Ferraz S, Santos JM (1990) Histopatologia de raízes de Crotalaria parasitadas por Meloidogyne javanica. Fitopatol. Bras. 15(1), 46-48.

Valle LAC, Ferraz S, Teixeira DA (1997) Estímulo à eclosão de juvenis, penetração e desenvolvimento de Heterodera glycinesem raízes de mucuna preta (Mucuna aterrima) e feijão guandu (Cajanus cajan). Nematol Bras. 21(1), 67-83.

Watanabe N, Lam E (2004) Recent advance in the study of caspase-like proteases and Bax inhibitor-1 in plants: their possible roles as regulator of programmed cell death. Mol Plant Pathol. 5(1), 65-70.

Williamson VM, Gleason CA (2003) Plant-nematode interactions. Curr Opin Plant Biol. 6(4):327-333.

Willianson VM, Hussey RS (1996) Nematode pathogenesis and resistance in plants. Plant Cell. 8(1), 1735-1745. 